\title{
POLA DISTRIBUSI DAN KERAPATAN ROTAN (Daemonorops robusta Warburg) DI HUTAN PEGUNUNGAN SEKITAR NOKILALAKI KECAMATAN PALOLO KABUPATEN SIGI SULAWESI TENGAH
}

\section{Distribution Patterns and Rattan Density (Daemonorops robusta Warburg) in the Mountain Forest Around Nokilalaki, Palolo District, Sigi Regency, Central Sulawesi}

\author{
Grisnayanti* dan Ramadanil
}

Jurusan Biologi Fakultas MIPA, Universitas Tadulako, Palu Jl. Soekarno-Hatta Km 9, Tondo Palu, Sulawesi Tengah 94117

Keywords: Distribution patterns, Daemonoro ps robusta Warburg, Nokilalaki

Kata Kunci: Pola Distribusi, Daemonoro ps robusta Warburg, Nokilalaki

\section{ABSTRACT}

Research entitled of "Distribution Patterns and Rattan Density (Daemonorops robusta Warburg) in the Mountain Forest Around Nokilalaki Palolo District, Sigi Regency, Central Sulawesi" has been carried out from December 2018 to February 2019. This study used an explorative survey method by exploring the Nokilalaki mountainous region, for the looking for $D$. robusta Warburg populations. The sampling process uses a transect line method measuring $50 \times 10 \mathrm{~m}$ with the placement of transects by purposive sampling of 7 pieces. The observations show that the Morisita Index results in D. Robusta Warburg namely clustering and the highest relative density value at the level of tillers is in transect I which is $32.4 \%$, the lowest in transect III is $8.1 \%$ and the highest relative density value at the adult level is in transect I $38.4 \%$ and the lowest in transect II and VI that is $11.5 \%$.

\section{ABSTRAK}

Penelitian tentang "Pola Distribusi dan Kerapatan Rotan (Daemonorops robusta Warburg) di Hutan Pegunungan Sekitar Nokilalaki Kecamatan Palolo Kabupaten Sigi Sulawesi Tengah" telah dilakasanakan dari bulan Desember 2018 sampai Februari 2019. Penelitian ini menggunakan metode survey eksploratif dengan menjelajah kawasan pegunungan Nokilalaki, untuk mencari populasi $D$. robusta Warburg. Proses pengambilan sampel menggunakan metode garis transek yang berukuran $50 \times 10 \mathrm{~m}$ dengan penempatan transek secara purposive sampling sebanyak 7 buah. Hasil pengamatan menunjukan bahwa hasil Indeks Morisita pada $D$. robusta Warburg yaitu mengelompok dan nilai kerapatan relatif tertinggi pada tingkat anakan terdapat pada transek I yaitu $32,4 \%$,terendah pada transek III yaitu $8,1 \%$ dan nilai kerapatan relatif tertinggi pada tingkat dewasa terdapat pada transek I 38,4\% dan terendah pada transek II dan VI yaitu $11,5 \%$.

*Corresponding Author : grisnayanti@gmail.com 


\section{PENDAHULUAN}

Palem di Sulawesi memiliki endemisitas yang tinggi (72\%), tergolong $68 \%$ spesies dan $58 \%$ genus palem yang tumbuh di bioregion. Jenisjenis palem yang endemik Sulawesi Tengah, yaitu Gronophyllum sarasinorum dan Pinanga sp. nov (longirachilla) Pigafeta elata Becc., Licuala celebica Miq., dan beberapa jenis rotan. Rotan tumbuh subur di daerah tropik, termasuk Indonesia. Di indonesia rotan tumbuh secara alami dan tumbuh luas di Jawa, Sumatera, Kalimantan, Sulawesi dan Irian Jaya (Papua) (Pitopang, 2002).

Rotan merupakan palem berduri yang berbatang tunggal (Soliter) atau berumpun. Rumpun terbentuk oleh berkembangnya tunas-tunas yang dihasilkan dari kuncup ketiak pada bagian bawah batang. Kuncup-kuncup tersebut berkembang sebagai rimpang pendek yang kemudian tumbuh menjadi batang diatas permukaan tanah. Rotan di Sulawesi hampir ditemukan disemua daerah seperti di Kendari, Kolaka, Toeuli, Donggala, Poso, Sigi, Buol, Toli-toli, Gorontalo, Palopo, dan Buton (Rustiami et al., 2017). Menurut (Mogea, 1990) di Sulawesi Tengah diperkirakan terdapat 28 jenis rotan. Salah satu rotan di Sulawesi yaitu Calamus, Korthalsia dan Daemonorops, untuk marga
Daemonorops memiliki beberapa jenis yang telah diketahui yaitu Daemonorops robusta Warburg, Daemonorops lamprolepis dan Daemonorops macroptera (Rustiami et al., 2017).

Daemonorops merupakan salah satu marga rotan yang termasuk dalam anak suku Calamoideae dengan jumlah jenis terbanyak kedua setelah Calamus, yaitu sekitar 120 jenis (Rustiami 2011). Marga Daemonorops dideskripsikan berdasarkan tipe spesies Daemonorops melanochaetes Blume. Persebaran Daemonorops dimulai dari India, Cina Selatan, Kepulauan Indonesia sampai Papua Nugini Barat dengan keanekaragaman terbesar ditemukan di Malesia Barat (Dransfield et al., 2008).

Karakter pembeda antar kedua marga, yaitu marga Calamus dan Daemonorops, dapat menggunakan tiga karakter untuk membedakan kedua marga secara umum, yaitu alat panjat, okrea dan pembunggaan. Marga Calamus mempunyai alat panjat flagela yang dikembangkan dari perbungaan yang termodifikasi dan tumbuh pada pelepah daun dan mempunyai okrea, sedangkan perbungaannya adalah braktea yang bentuknya seperti tabung dan tidak luruh pada saat bunga mekar. Pada marga Daemonorops mempunyai alat 
panjat sirus/sulur yang merupakan organ panjat yang di kembangkan oleh perpanjangan daun dan tidak memiliki okrea. Pada Daemonorops robusta Warburg terdapat seludang atau daun pelindung yang menyelubungi bunga majemuk disaat bunga majemuk belum mekar (Rustiami, 2011).

Rotan Daemonorops robusta Warburg juga didapatkan di Sulawesi Tengah, khususnya di Taman Nasional Lore Lindu (TNLL), namun informasi mengenai pola distribusi dan kerapatan jenis Daemonorops robusta Warburg di kawasan ini belum banyak diketahui. Maka dari itu dilakukannya penelitian mengenai pola distribusi dan kerapatan Daemonorops robusta Wargburg di Hutan Pegunungan sekitar Nokilalaki Kecamatan Palolo Kabupaten Sigi.

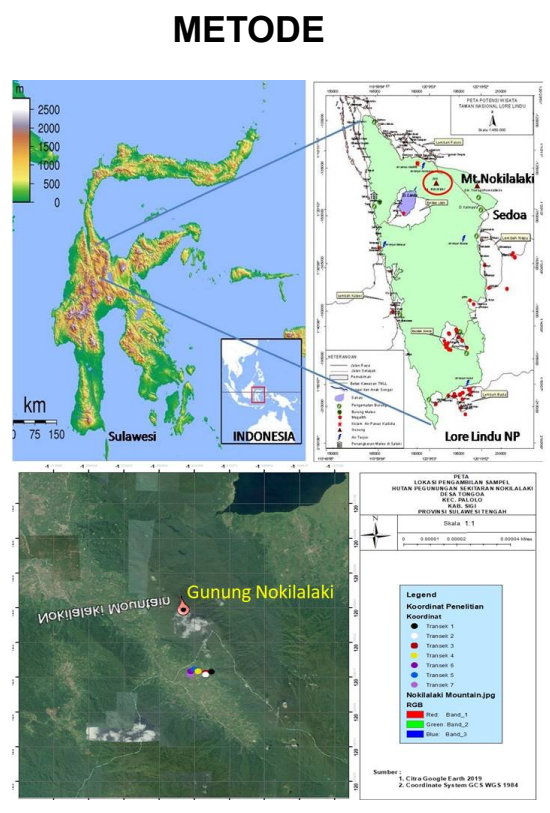

Gambar1. Peta Lokasi Penelitian ISSN-P : 1978-6417; ISSN-E : 2580-5991

\section{Bahan dan Metode}

Bahan yang digunakan pada penelitian ini yaitu tali, sasak, spritus, kertas label, koran dan plastik. Alat yang digunakan pada penelitian ini yaitu global positioning system (GPS), meteran, patok, oven listrik (electric stove), kamera, tongkat atau gala untuk memotong sampel yang letaknya tinggi, soil tester untuk mengukur $\mathrm{pH}$ tanah dan kelembaban tanah, parang dan alat tulis.

\section{Prosedur Kerja}

Penelitian ini menggunakan metode survey eksploratif dengan menjelajah Kawasan Hutan Pegunungan Nokilalaki, untuk mencari populasi Daemonorops robusta Warburg. Sementara untuk proses pengambilan sampel yakni dengan metode transek yang berukuran 50×10 m dengan penempatan secara purpsive sampling. Sampling dilakukan secara sengaja pada titik yang memungkikan adanya sampel pada setiap wilayah yang ditentukan (Kusuma, 1997). Setelah menemukan populasinya kemudian pengambilan sampel dengan membuat transek sebanyak 7 buah. Dalam satu rumpun akan dinyatakan sebagai satu individu. 


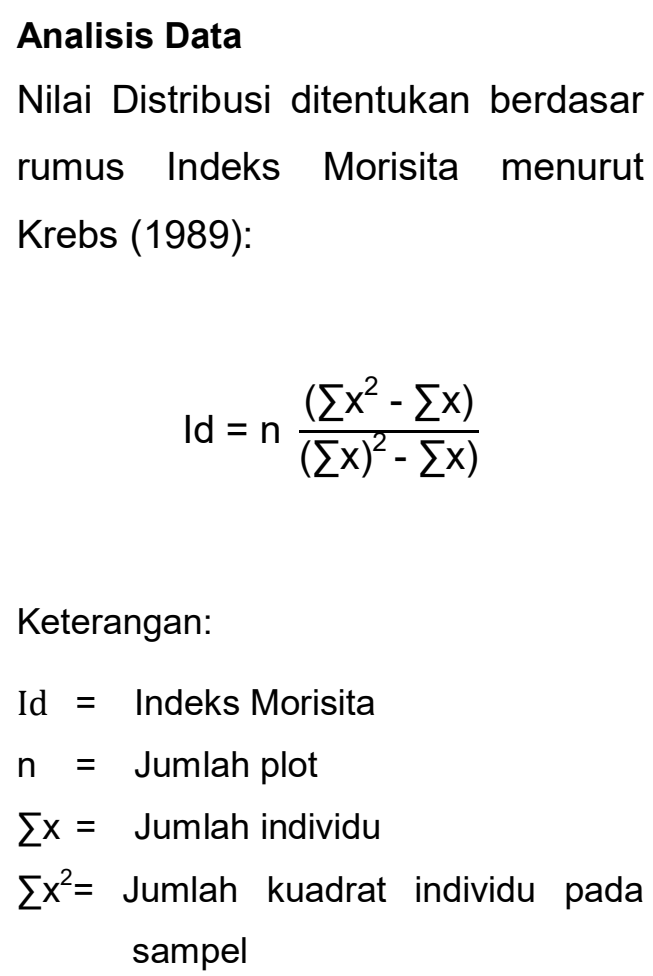

Kerapatan populasi adalah jumlah populasi dalam hubungannya dengan satuan ruang. Kerapatan juga dapat mempermudah memberikan gambaran susunan mengenai jenis suatu komunitas (Kusuma, 1997).

Menghitung kerapatan (density) menggunakan rumus menurut (Kusuma, 1997) sebagai berikut:

$$
\begin{aligned}
& \text { Kerapatan }(\mathrm{k}) \quad= \\
& \frac{\text { Jumlah Individu }}{\text { Luas Area Petak-Ha }} \\
& \mathrm{KR}=\frac{\text { Kerapatan individu }}{\text { Kerapatan seluruh spesies }} \times 100 \%
\end{aligned}
$$

\section{HASIL DAN PEMBAHASAN}

Berdasarkan hasil yang diperoleh dari pengamatan di lapangan ditemukan spesies Daemonorops robusta Warburg pada elevasi 1730-1200 mdpl dengan data ekologi yang disajikan pada tabel 1 . Pada tabel 2 disajikan hasil pola distribusi $D$. robusta Warburg dengan jumlah individu anakan 37 individu/ha dan jumlah individu dewasa 26 individu/ha yang menunjukan individu dari $D$. robusta Warburg hidup mengelompok. Kerapatan pada Tumbuhan $D$. robusta Warburg disajikan pada tabel 3 dengan nilai kerapatan tertinggi terdapat pada tingkat anakan dan kerapatan relatif terdapat pada tingkat dewasa. 
Tabel 1. Data Ekologi Lokasi Penelitian

\begin{tabular}{cccc}
\hline Transek & $\mathrm{pH}$ Tanah & Kelembaban (\%) & Intensitas Cahaya (lux) \\
\hline I & 5 & 60 & $2245 \operatorname{lux}$ \\
II & 4,2 & 70 & $4320 \operatorname{lux}$ \\
III & 5 & 60 & $12560 \operatorname{lux}$ \\
IV & 4,2 & 60 & $2750 \operatorname{lux}$ \\
V & 4,8 & 65 & $4560 \operatorname{lux}$ \\
VI & 4 & 80 & $11025 \operatorname{lux}$ \\
VII & 5 & 60 & $12254 \operatorname{lux}$ \\
\hline
\end{tabular}

Tabel 2. Pola Distribusi Daemonorops robusta Warburg.

\begin{tabular}{cccccccc}
\hline No & Transek & \multicolumn{2}{c}{$\begin{array}{c}\text { Jumlah Individu } \\
\text { dalam Transek }\end{array}$} & \multicolumn{2}{c}{ Indeks Morisita } & \multicolumn{2}{c}{ Pola Distribusi } \\
\hline & & Anakan & Dewasa & Anakan & Dewasa & Anakan & Dewasa \\
1 & I & 12 & 10 & 0,04 & 0,13 & Mengelompok & Mengelompok \\
2 & II & 4 & 3 & 0,33 & 0,53 & Mengelompok & Mengelompok \\
3 & III & 3 & - & 0,53 & - & Mengelompok & - \\
4 & IV & 8 & 5 & 0,09 & 0,22 & Mengelompok & Mengelompok \\
5 & V & 6 & - & 0,16 & - & Mengelompok & - \\
6 & VI & 4 & 3 & 0,33 & 0,53 & Mengelompok & Mengelompok \\
7 & VII & - & 5 & - & 0,22 & & Mengelompok \\
\hline
\end{tabular}

Tabel 3. Kerapatan tumbuhan Daemonorops robusta Warburg

\begin{tabular}{|c|c|c|c|c|c|c|c|}
\hline \multirow[t]{2}{*}{ No } & \multirow[t]{2}{*}{ Transek } & \multicolumn{2}{|c|}{$\begin{array}{c}\text { Jumlah individu dalam } \\
\text { Transek }\end{array}$} & \multicolumn{2}{|c|}{ Kerapatan } & \multicolumn{2}{|c|}{ Kerapatan Relatif } \\
\hline & & Anakan & Dewasa & Anakan & Dewasa & Anakan & Dewasa \\
\hline 1 & I & 12 & 10 & 240 & 200 & $32,4 \%$ & $38,4 \%$ \\
\hline 2 & II & 4 & 3 & 80 & 60 & $10.8 \%$ & $11,5 \%$ \\
\hline 3 & III & 3 & - & 60 & - & $8,1 \%$ & 0 \\
\hline 4 & IV & 8 & 5 & 160 & 100 & $21,6 \%$ & $19,2 \%$ \\
\hline 5 & V & 6 & - & 120 & - & $16,2 \%$ & 0 \\
\hline 6 & VI & 4 & 3 & 80 & 60 & $10.8 \%$ & $11,5 \%$ \\
\hline 7 & VII & - & 5 & - & 100 & - & $19,2 \%$ \\
\hline & Total & 37 & 26 & 740 & 520 & $100 \%$ & $100 \%$ \\
\hline
\end{tabular}




\section{PEMBAHASAN}

Hasil pengamatan di lapangan ditemukan spesies Daemonorops robusta Warburg dengan jumlah individu pada tingkat anakan 37 individu dan pada tingkat dewasa 26 individu.Faktor ketinggian juga mempengaruhi banyaknya individu, semakin tinggi suatu tempat, semakin jarang ditemukannya tumbuhan $D$. robusta Warburg dan terdapat tumbuhan lain yang hidup bersamaan seperti kelompok tumbuhan Caryota. Pada hasil pengamatan ketinggian pada tiap transek berbeda-beda, pada transek VII memiliki ketinggian yaitu 1730 mdpl yang berarti pada transek ini jarang ditemukan individu $D$. robusta Warburg sedangkan pada transek I memiliki ketinggian $1200 \mathrm{mdpl}$ dan banyak terdapat individu $D$. robusta Warburg. Agung (2008) menyatakan bahwa pada kondisi lingkungan tertentu, setiap jenis tumbuhan tersebar dengan tingkat adaptasi yang beragam, sehingga menyebabkan hadir atau tidaknya suatu jenis tumbuhan pada lingkungan.

Tabel 1 terlihat hasil data ekologi pada $\mathrm{pH}$ tanah, kelembaban (\%), robusta Warburg dengan nilai 12560. Menurut Silvikutur (2007), cahaya berpengaruh terhadap arah dan intensitas cahaya (lux) yaitu $\mathrm{pH}$ tanah yang memiliki sifat asam dengan nilai $\mathrm{pH}$ tanah berkisar 4-5. Pentingnya $\mathrm{pH}$ tanah menentukan mudah tidaknya unsur-unsur hara diserap tumbuhan, umumnya unsur hara mudah diserap akar pada sekitar $\mathrm{pH}$ tanah netral, karena pada $\mathrm{pH}$ tersebut kebanyakan unsur hara mudah larut dalam air (Hardjowigeno, 2007).

Nilai kelembaban berkisar antara 60 - 80 \% dan intensitas cahaya matahari pada lokasi penelitian mencapai 2245 - 12560 lux. Kondisi tanah pada lokasi penelitian tergolong lembab. Perubahan kondisi kandungan kelembaban tanah, sangat kering pada musim kemarau dan sangat basah pada musim penghujan perlu diperhatikan sehingga nantinya keadaan tanah dapat digunakan untuk tingkat produktivitas yang baik (Arnold, 1999). Hasil pengematan tumbuhan D. robusta Warburg sering ditemukan pada daerah yang memiliki intensitas cahaya yang rendah yaitu pada transek I dengan nilai 2245 lux sedangkan pada daerah yang tinggi pada transek III jarang ditemukan tumbuhan $D$. pertumbuhan akar. Intensitas cahaya yang masuk secara berlebihan akan mengakibatkan 
terhambatnya perkecambahan dan dapat meningkatkan ukuran jumlah kematian spesies-spesies yang tidak tahan cahaya (Rasnovi, 2006). Tabel 2 terlihat hasil pola distribusi dan Indeks Morisita Dari hasil analisis data yang didapatkan di lapangan. Hasil indeks morisita pada tingkat anakan dengan nilai yang terendah terletak pada transek I yaitu 0,04 dengan titik koordinat $\mathrm{S} 01^{\circ} 19^{\prime} 04$, 52 " dan E $120^{\circ} 18$ '29, 10" yang terdapat pada ketinggian $1200 \mathrm{mdpl}$ yang berarti pola distribusinya mengelompok karena indeks Morisita $>0$, sedangkan nilai tertingi tingkat anakan pada hasil indeks morisita terletak pada transek III yaitu 0,53 pada titik koordinat $\mathrm{S} 01^{0}$ $19^{\prime} 20$, 3" dan E $120^{\circ} 18$ '31, 14" dengan ketinggian 1690 mdpl yang berarti pola distribusinya mengelompok.

Hasil indeks morisita pada tingkat dewasa nilai terendah terletak pada transek I yaitu 0,13 dengan ketinggian 1200 mdpl dengan titik koordinat S $01^{0} 19^{\prime} 04,52$ " dan E $120^{\circ} 18 ' 29,10$ " yang berarti pola distribusinya mengelompok sedangkan nilai indeks morisita yang tertinggi pada tingkat dewasa terletak pada transek II dan VII yaitu 0,53 yang berarti pola distribusinya mengelompok. Penyebaran mengelompok dapat meningkatkan persaingan antara populasi untuk memperoleh unsur hara, ruang dan cahaya. Menurut Greig-Smith (1983) Pola penyebaran spesies tumbuhan dipengaruhi oleh perbedaan kondisi tanah, sumber daya, dan persaingan. Indeks Morisita adalah metode terbaik untuk mengukur pola sebaran suatu individu karena tidak bergantung terhadap kepadatan populasi dan ukuran sampel contoh yang diambil (Rani, 2003). Kerapatan populasi sangat ditentukan oleh berbagai faktor yaitu kelahiran atau regenerasi, kematian, perpindahan masuk, dan perpindahan keluar (Syafei 1994).

Tabel 3 terlihat hasil nilai kerapatan dan kerapatan relatif pada tumbuhan Daemonorops robusta Warburg kerapatan yang terendah pada tingkat anakan tumbuhan $D$. robusta Warburg yaitu pada transek III dengan nilai 60 dan nilai kerapatan relatif $8,1 \%$ sedangkan pada tingkat dewasa nilai kerapatan yang terendah terletak pada transek II dan VI dengan nilai kerapatan 60 dan mempunyai nilai kerapatan relatif $11,5 \%$ dan nilai tertinggi tingkat anakan terletak pada transek I yang mempunyai nilai kerapatan 240 dan kerapatan relatif $32,4 \%$ sedangkan pada tingkat dewasa nilai kerapatan 
tertinggi terletak pada transek I dengan nilai kerapatan 200 dan nilai kerapatan relatif $38,4 \%$. Total dari nilai kerapatan tumbuhan $D$. robusta Warburg pada tingkat anakan bernilai 740 dan tingkat dewasa bernilai 520 sehingga kemampuan dalam bergenerasi masih cukup baik.

Dari hasil pengamatan maka nilai kerapatan yang tertinggi dapat dianggap sebagai jenis yang rapat serta tersebar luas pada hampir seluruh lokasi pengamatan Namun pada saat penelitian ditemukan beberapa tumbuhan $D$. Robusta Warburg yang telah rusak disebabkan oleh beberapa faktor ekologis seperti aktifitas manusia seperti penebangan pohon secara tidak berencana dan karena musim atau bencana alam yang menyebabkan penurunan ukuran

\section{DAFTAR PUSTAKA}

Agung, K. dan Parikesit. (2008). Persebaran Jenis Pohon Di Sepanjang Faktor Lingkungan Di Cagar Alam Pananjung Pangandaran. Jawa Barat: Biodiversitas Volume 9, Nomor 4 Oktober 2008 Halaman: 275279.

Arnold, James, E. (1999). Soil Moisture. USA: GHCC, Inc. populasi baik untuk sementara maupun untuk waktu yang relatif lama (Ewuisie, 1980).

\section{KESIMPULAN}

Berdasarkan hasil dari penelitian dapat disimpulkan bahwa Pola distribusi tumbuhan Daemonorops robusta Warburg di hutan Pegunungan sekitar Nokilalaki Kecamatan Palolo Kabupaten Sigi Sulawesi Tengah tumbuh mengelompok. Nilai kerapatan tertinggi terdapat pada tingkat anakan terdapat pada transek I berjumlah 200 individu/ha dan nilai kerapatan relatif tertinggi pada $t$ ingkat anakan terdapat pada transek I yaitu $32,4 \%$ dan terendah pada transek III yaitu $8,1 \%$ dan nilai kerapatan tertinggi pada tingkat dewasa terdapat pada transek I yaitu $38,4 \%$ dan terendah pada transek II dan VI yaitu $11,5 \%$.

Dransfield, J.dan Monokaran, N. 2008. A synopsis of the genus Daemonorops. Kew Bulletin, 36(1), 163-194.

Ewuisie, J. Y. (1980). Ekologi Tropika. Membicarakan alam tropika: Afrika. Jurnal Ekologi Dasar 16(2), 63-68

Greig-Smith, P. (1983). Quantitative Plant Ecology. lowa: University Press. 
Hardjowigeno (2007) Ilmu Tanah. Jakarta: Penerbit Pustaka Utama.

Kusuma, C. (1997). Metode survei vegetasi. Bogor: Institut Pertanian Bogor.

Krebs, C. J. (1989). Ecologycal methodology. New York: Harper and Row publisher.

Mogea, J.P. (1990). Preliminary studi on the palm flora of the Lore Lindu National Park, Central Sulawesi, Indonesia. Biotropia. 18, 1-20.

Pitopang, R., and Gradstein, S. R. (2002). Tree composition in secondary forest of Lore Lindu National Park, Central Sulawesi Indonesia. Abstract, International Symposium on Land Use, Nature Conservation and the Stability of Rainforest Margins in Southeast Asia, Bogor, 29 September - 3 October 2002.

Syafei, E. S. (1994). Pengantar ekologi tumbuhan. Institut Teknologi Bandung Fakultas
Rani, C. (2003). Metode pengukuran dan analisi pola spasial (Dispresi) organisme bentik. Fakultas IImu Kelautan dan Perikanan. Makasar: UNHAS.
Rasnovi, S., (2006). Ekologi Regenerasi Tumbuhan Berkayu Pada Sistem Agroforest Karet. Disertasi. Bogor: Program Pascasarjana Institut Pertanian Bogor.

Rustiami, H. (2011). Revision of Calamus and Daemonorops (Arecaceae) in Sulawesi (disertasi). Bogor (ID): Program Pascasarjana, Institut Pertanian Bogor.

Rustiami, H. And Henderson, A. (2017). A synopsis of Calamus (Arecaceae) in Sulawesi, Indonesia: Reinwardita 16(2): 49-63.

Silvikultur. (2007). Sumber Cahaya Matahari. Jakarta: Pakar Raya.

Matematika dan IImu Pengetahuan Alam 